TITLE:

\title{
An ionic liquid state composed of superoxide radical anions and crownether-coordinated potassium cations
}

\section{$\operatorname{AUTHOR}(\mathrm{S}):$}

Kitada, Atsushi; Ishikawa, Daisuke; Fukami, Kazuhiro; Murase, Kuniaki

\section{CITATION:}

Kitada, Atsushi ...[et al]. An ionic liquid state composed of superoxide radical anions and crownether-coordinated potassium cations. Journal of the Electrochemical Society 2017, 164(8): H5119-H5123

ISSUE DATE:

2017-05-06

URL:

http://hdl.handle.net/2433/240666

\section{RIGHT:}

(c) The Author(s) 2017. Published by ECS. This is an open access article distributed under the terms of the Creative Commons Attribution 4.0 License (CC BY, http://creativecommons.org/licenses/by/4.0/), which permits unrestricted reuse of the work in any medium, provided the original work is properly cited. 


\title{
An Ionic Liquid State Composed of Superoxide Radical Anions and Crownether-Coordinated Potassium Cations
}

\author{
Atsushi Kitada, ${ }^{\mathrm{Z}}$ Daisuke Ishikawa, Kazuhiro Fukami, ${ }^{*}$ and Kuniaki Murase* \\ Department of Materials Science and Engineering, Kyoto University, Sakyo-ku, Kyoto 606-8501, Japan
}

\begin{abstract}
We report an "ionic liquid state" substance composed of superoxide radical anions $\left(\mathrm{O}_{2}^{-}\right)$and crownether-coordinated potassium cations. A binary mixture of 18 -crown-6-ether (18C6) and potassium superoxide $\left(\mathrm{KO}_{2}\right)$ becomes liquid above ca. $38^{\circ} \mathrm{C}$. The coordination of $18 \mathrm{C} 6$ to $\mathrm{K}^{+}$and the presence of $\mathrm{O}_{2}^{-}$were confirmed in the liquid state by Raman spectroscopy measurements. Below $38^{\circ} \mathrm{C}$, however, the $18 \mathrm{C} 6-\mathrm{KO}_{2}$ mixture does not form a complex but undergoes phase separation to parent phases of solid $18 \mathrm{C} 6$ and $\mathrm{KO}_{2}$, because the ion-dipole interaction between $\mathrm{K}^{+}$and $18 \mathrm{C} 6$ is overwhelmed by the ion-ion interaction between $\mathrm{K}^{+}$and $\mathrm{O}_{2}{ }^{-}$. In other words, the pair of $\mathrm{O}_{2}^{-}$and 18C6-coordinated $\mathrm{K}^{+}$only appears above the melting point of pure $18 \mathrm{C} 6$, to form an "ionic liquid state". Among radical-containing ionic liquids, the liquid $18 \mathrm{C} 6-\mathrm{KO}_{2}$ mixture has high fluidity and comparable conductivity. The findings show stabilization of superoxide radical anions at liquid state with high concentration, which could be used for many radical reactions.

(C) The Author(s) 2017. Published by ECS. This is an open access article distributed under the terms of the Creative Commons Attribution 4.0 License (CC BY, http://creativecommons.org/licenses/by/4.0/), which permits unrestricted reuse of the work in any medium, provided the original work is properly cited. [DOI: 10.1149/2.0131708jes] All rights reserved.

(cc) BY
\end{abstract}

Manuscript submitted February 10, 2017; revised manuscript received April 17, 2017. Published May 6, 2017. This was Paper 1417 presented at the Cancun, Mexico, Meeting of the Society, October 5-9, 2014. This paper is part of the JES Focus Issue on Progress in Molten Salts and Ionic Liquids.

Superoxide anion $\mathrm{O}_{2}^{-}$is a one-electron reduced state of oxygen molecule $\left(\mathrm{O}_{2}+\mathrm{e} \rightarrow \mathrm{O}_{2}^{-}\right)$. The one unpaired electron is a radical, making $\mathrm{O}_{2}^{-}$a radical anion. $\mathrm{O}_{2}^{-}$radical has many uses such as radical polymerization, ${ }^{1,2}$ decomposition of halogenated organics in waste water. ${ }^{3}$ For those purposes potassium superoxide $-\mathrm{KO}_{2}$, a yellow solid at room temperature (RT) — has been used as a radical source. ${ }^{3-5}$ Since $\mathrm{O}_{2}{ }^{-}$is decomposed in protic solvents (e.g. $2 \mathrm{O}_{2}{ }^{-}+$ $\mathrm{H}_{2} \mathrm{O} \rightarrow \mathrm{O}_{2}+\mathrm{HO}_{2}^{-}+\mathrm{OH}^{-}$and $2 \mathrm{HO}_{2}^{-} \rightarrow \mathrm{O}_{2}+2 \mathrm{OH}^{-}$), aprotic solvents were used to dissolve $\mathrm{KO}_{2}$. For example, a highly polar aprotic solvent, dimethylsulfoxide (DMSO), was used with a cyclic ionophore dicyclohexyl-18-crown-6-ether (D18C6) to prepare $\mathrm{KO}_{2}$ solution. ${ }^{5}$

The highest concentration of $\mathrm{O}_{2}{ }^{-}$in organic solution, however, is only $0.15 \mathrm{~mol} \mathrm{dm}^{-3}$ in D18C6-containing DMSO solution, i.e. $\mathrm{KO}_{2}:$ D18C6:DMSO $=1: 2: 100$ by mole. ${ }^{5} \mathrm{O}_{2}^{-}$solutions can also be obtained chemically or electrochemically in aprotic solvents including ionic liquids, but the concentrations are small. ${ }^{6-10}$ Therefore, drastic increase in superoxide radical concentration is of interest; for this purpose, designing novel superoxide radical compounds in liquid state is necessary.

Examples of known superoxides are alkaline and alkaline-earth metal superoxides, of which magnetism have attracted attention. ${ }^{11-15}$ These counter cations have small ionic radii and high charge densities, i.e. they were "hard acids" to give strong cation-anion interactions and melting points much higher than RT. From this viewpoint, larger counter cations need to be designed. There are several superoxides using large cations such as quaternary ammonium cations, but their liquid properties are missing due to rapid decomposition. ${ }^{16,17}$ An alternative approach for novel "superoxide liquids" may be coordination of metal cations by ethers. This is because ethers were judged to be more stable to $\mathrm{O}_{2}{ }^{-}$attack than organic carbonates, ${ }^{18}$ which attracted attention as metal-air battery electrolytes. ${ }^{19-23}$ It is also because ethers have been used to prepare so-called "solvate ionic liquids", where ether-coordinated metal cations are component cations. ${ }^{24-28}$

Our preliminary results showed that an equimolar mixture of 18crown-6-ether (18C6) and potassium superoxide $\left(\mathrm{KO}_{2}\right)$ becomes liquid above $41^{\circ} \mathrm{C}$, without sizable decomposition of $\mathrm{O}_{2}^{-}$, while equimolar mixtures of $\mathrm{KO}_{2}$ and other ethers such as glymes and D18C6 rapidly decomposed. ${ }^{29}$ In this work, we study the detailed physico-

*Electrochemical Society Member.

${ }^{\mathrm{z}}$ E-mail: kitada.atsushi.3r@kyoto-u.ac.jp chemical properties of $18 \mathrm{C} 6-\mathrm{KO}_{2}$ mixture: in addition to our earlier work, ${ }^{29}$ we performed conductivity and viscosity measurements in the liquid state and Raman measurements in the solid state. From these new results a peculiar phase separation behavior was observed below the melting point; also, the "ionicity" - i.e. degree of cationanion dissociation - of the $18 \mathrm{C} 6-\mathrm{KO}_{2}$ equimolar molten mixture is discussed.

\section{Experimental}

Preparation.-C(Caution! Superoxide salts with organic cations are potentially explosive and should be handled with care and in small quantity only.) $\mathrm{KO}_{2}$ (Kanto Chemical) and 18-crown-6-ether (18C6, Kanto Chemical) were kept in an Ar-filled glove box $\left(\mathrm{H}_{2} \mathrm{O}, \mathrm{O}_{2}<1\right.$ $\mathrm{ppm}$ ) and used without further purification. The water content of $18 \mathrm{C} 6$ was approximately $600 \mathrm{ppm}$ before use. $1.69 \mathrm{mmol}(120 \mathrm{mg})$ of $\mathrm{KO}_{2}$ and equimolar $18 \mathrm{C} 6$ were mixed in the glove box, stirred at $500 \mathrm{rpm}$, and heated at $50^{\circ} \mathrm{C}$ for $30 \mathrm{~min}$. Molar ratio of ether: $\mathrm{KO}_{2}$ was varied from $256: 1$ to $1: 1$ for $18 \mathrm{C} 6$.

Characterization.-An integrated Raman system (B\&W Tek, innoRam 785) was used for Raman spectroscopy measurements at RT, consisting of a semiconductor laser light source $(785 \mathrm{~nm})$, an axial transmissive spectrograph, a holographic probe head, and a CCD detector. The samples were sealed under Ar with septum and then measured within $30 \mathrm{~min}$ after taken out from a glove box. The spectral acquisition time, i.e., exposure time of CCD and the number of exposures was varied for each sample so as to improve the signal-tonoise ratio of each spectrum. Conductivity measurements were performed by means of ac impedance method at $50^{\circ} \mathrm{C}$ using a Radiometer Analytical CDM230. Viscosity measurements were conducted using SEKONIC VM-10A calibrated using a standard solution (JS2.5; NIPPON GREASE Co., Ltd.). Conductivity and viscosity were measured in a dry-air filled chamber $\left(<40 \mathrm{ppm}_{2} \mathrm{O}\right)$. Magnetization measurements were conducted to detect $\mathrm{O}_{2}{ }^{-}$content using superconducting quantum interference device (SQUID, Quantum Design) at $0.1 \mathrm{~T}$ between $5 \mathrm{~K}$ and $300 \mathrm{~K}$ with zero field cooling process. The melting points were evaluated by differential scanning calorimeter (DSC60, SHIMADZU). The samples with $2-5 \mathrm{mg}$ were sealed in aluminum pans and scanned at a rate of $1 \mathrm{~K} \mathrm{~min}^{-1}$ by heating from $0^{\circ} \mathrm{C}$ to $55^{\circ} \mathrm{C}$, holding at $55^{\circ} \mathrm{C}$ for $5 \mathrm{~min}$, and then cooling down to RT under dry $\mathrm{N}_{2}$ gas flow. 

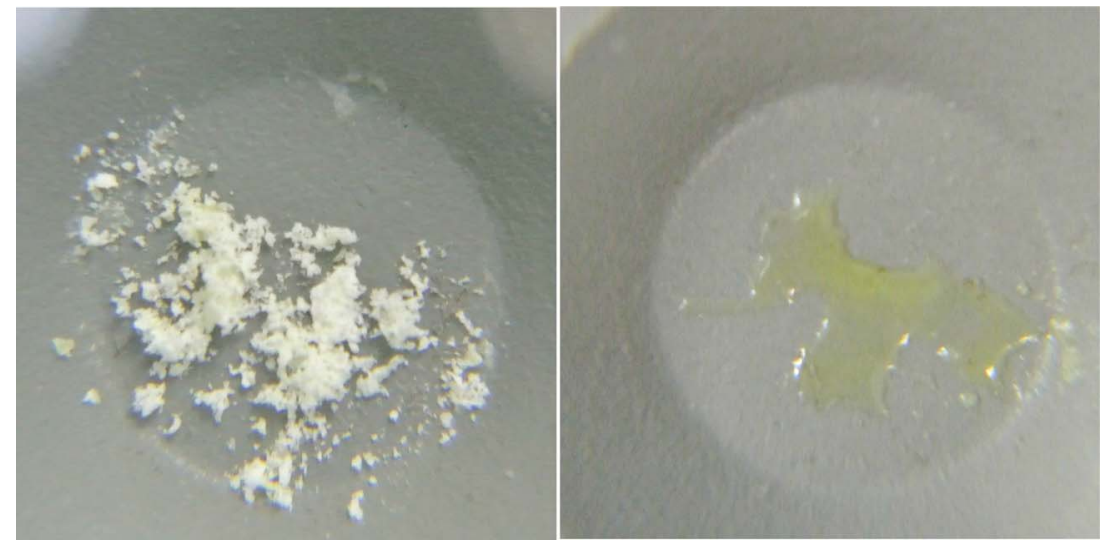

Figure 1. Photographs of $18 \mathrm{C} 6-\mathrm{KO}_{2}$ equimolar mixture: pale-yellow solid at $25^{\circ} \mathrm{C}$ (left) and yellow liquid at 38 $42^{\circ} \mathrm{C}$ (right).

\section{Results and Discussion}

Appearance of the prepared sample.-The 1:1 mixture of $\mathrm{KO}_{2}$ and 18 -crown-6-ether heated at $50^{\circ} \mathrm{C}$ for $30 \mathrm{~min}$ became a yellow liquid. When the 1:1 18C6- $\mathrm{KO}_{2}$ mixture was cooled to RT it became a pale-yellow solid (see Fig. 1, left panel) and when reheated it melted to be a clear yellow liquid again at $38-42^{\circ} \mathrm{C}$ (see Fig. 1, right panel). We predict that the strong coordination ability of these crown ethers to $\mathrm{K}^{+}$cation contributed to the sizable decrease in charge density of cations and thereby the melting point of the superoxide became near RT. Notably, the melting point of $\mathrm{KO}_{2}$ is above $500{ }^{\circ} \mathrm{C},{ }^{30}$ thus one can say that the cation complexation drastically decreased its melting point to near RT. Using DMSO such complexation that decreases melting point of $\mathrm{KO}_{2}$ does not occur; instead, $\mathrm{KO}_{2}$ dissolves sparingly in DMSO. ${ }^{5}$ This means that the lattice free energy of $\mathrm{KO}_{2}$ is so large that a lot of DMSO molecules are needed for dissolution. In the case of $18 \mathrm{C} 6$, however, only equimolar amount is needed, revealing the ion-dipole interaction between $\mathrm{K}^{+}$and $18 \mathrm{C} 6$ is much larger than that between $\mathrm{K}^{+}$and DMSO.

Raman spectroscopy at liquid state.-To check the coordination environment at liquid state, Raman measurements were conducted at $50^{\circ} \mathrm{C}$ for the $1: 118 \mathrm{C} 6-\mathrm{KO}_{2}$ mixture and pure $18 \mathrm{C} 6$ (see Fig. 2). For $18 \mathrm{C} 6-\mathrm{KO}_{2}$ mixture liquid, bands evolved between 860 and $900 \mathrm{~cm}^{-1}$, which were not seen in pure 18C6 liquid. The Raman band centered at $870 \mathrm{~cm}^{-1}$ corresponds to the combination of $\mathrm{CH}_{2}$ rocking and COC stretching modes of $18 \mathrm{C} 6$ molecules which coordinate $\mathrm{K}^{+}$: the bands at $870 \mathrm{~cm}^{-1}$ have been commonly seen in alkaline metal salts in ether solutions, i.e. breathing mode. ${ }^{24,25}$ The presence of $\mathrm{O}_{2}{ }^{-}$ion is confirmed by the Raman spectrum between $1110 \mathrm{~cm}^{-1}$ and 1160 $\mathrm{cm}^{-1}$ of the $1: 118 \mathrm{C} 6-\mathrm{KO}_{2}$ at $50^{\circ} \mathrm{C}$, where bands characteristic to superoxide anion are observed $\left(1143 \mathrm{~cm}^{-1}\right.$; see Fig. 3$) .^{22,23}$ Below we denote the liquid state of $1: 118 \mathrm{C} 6-\mathrm{KO}_{2}$ mixture as $[18 \mathrm{C} 6 \cdot \mathrm{K}]\left[\mathrm{O}_{2}\right]$, to emphasize the complex formation.

Bath properties.-Figure 4 shows bath properties of $[18 \mathrm{C} 6 \cdot \mathrm{K}]\left[\mathrm{O}_{2}\right]$ at $50^{\circ} \mathrm{C}$ as a function of concentration. Both conductivities and viscosities change by molar ratio, indicating that $\mathrm{KO}_{2}$ totally dissolves into $18 \mathrm{C} 6$ at these mixing ratio. The conductivity and viscosity of $\left[18 \mathrm{C} 6 \cdot \mathrm{K}^{-}\left[\mathrm{O}_{2}\right]\right.$ at $50^{\circ} \mathrm{C}$ is $30.6 \mathrm{mPa} \mathrm{s}$ and $7.0 \mu \mathrm{S} \mathrm{cm}$, respectively. The viscosity was approximately twice as large as that of pure $18 \mathrm{C} 6(12.8 \mathrm{mPa}$ s). The conductivity of pure $18 \mathrm{C} 6$ was too low to measure; the value was below the limit, i.e. less than $0.01 \mu \mathrm{S} \mathrm{cm}^{-1}$. This evidences presence of ionic species in $[18 \mathrm{C} 6 \cdot \mathrm{K}]\left[\mathrm{O}_{2}\right]$, i.e. crownether-coordinated $\mathrm{K}^{+}$cations and superoxide $\mathrm{O}_{2}{ }^{-}$anions.

The poor conductivity with high fluidity may be attributed to high ionic association in the molten $[18 \mathrm{C} 6 \cdot \mathrm{K}]\left[\mathrm{O}_{2}\right]$. At $50^{\circ} \mathrm{C}$, the molar conductivity $\left(\Lambda_{\text {imp }}\right)$ of molten $[18 \mathrm{C} 6 \cdot \mathrm{K}]\left[\mathrm{O}_{2}\right]$ obtained from the ac impedance measurement is $1.6 \times 10^{-3} \mathrm{~S} \mathrm{~cm}^{2} \mathrm{~mol}^{-1}$, while its fluidity $\left(\eta^{-1}\right)$ is 3.27 Poise ${ }^{-1}$. In an ideal $\mathrm{KCl}$ aqueous solution $\mathrm{K}^{+}$and $\mathrm{Cl}^{-}$ ions are completely dissociated and act in an independent fashion. Here $\Lambda_{\text {ideal }}$ is assumed to be the ideal molar conductivity at a given fluidity of the ideal $\mathrm{KCl}$ aqueous solution. In other words, the absolute value of $\Lambda_{\text {ideal }}\left(\mathrm{S} \mathrm{cm}^{2} \mathrm{~mol}^{-1}\right)$ is equal to that of fluidity, $\eta^{-1}$ (Poise $\left.{ }^{-1}\right)$. Thus, $\Lambda_{\text {ideal }}$ of molten $[18 \mathrm{C} 6 \cdot \mathrm{K}]\left[\mathrm{O}_{2}\right]$ at $50^{\circ} \mathrm{C}$ is $3.27 \mathrm{~S} \mathrm{~cm}^{2} \mathrm{~mol}^{-1}$. Instead of $\Lambda_{\text {ideal }}$, the molar conductivity estimated from NMR (iondiffusivity) measurements $\left(\Lambda_{\mathrm{NMR}}\right)$ is often used to estimate the ionicity as a conductivity ratio $\Lambda_{\text {imp }} / \Lambda_{\mathrm{NMR}} \cdot{ }^{24,31}$ However, $\Lambda_{\text {imp }} / \Lambda_{\mathrm{NMR}}$ is not available for $[18 \mathrm{C} 6 \cdot \mathrm{K}]\left[\mathrm{O}_{2}\right]$ because the NMR method is restricted to the NMR-active nuclei. It is also notable that $\Lambda_{\mathrm{NMR}}$ and $\Lambda_{\text {ideal }}$ have

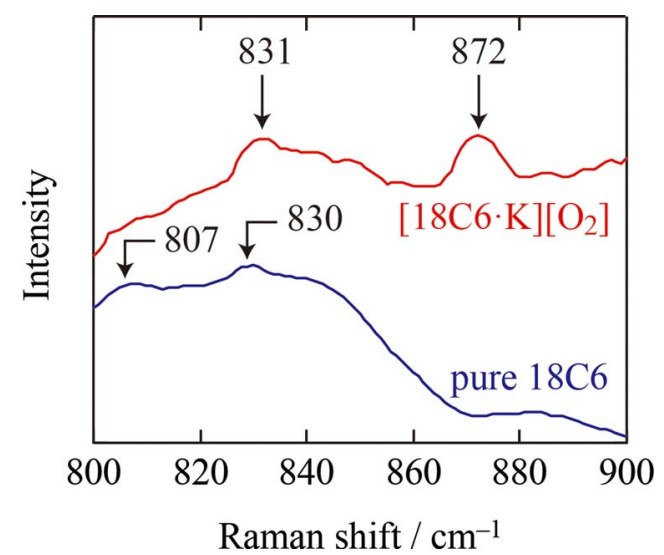

Figure 2. Raman spectra between $800-900 \mathrm{~cm}^{-1}$ for $18 \mathrm{C} 6$ and $[18 \mathrm{C} 6 \cdot \mathrm{K}]\left[\mathrm{O}_{2}\right]$ at $50^{\circ} \mathrm{C}$.

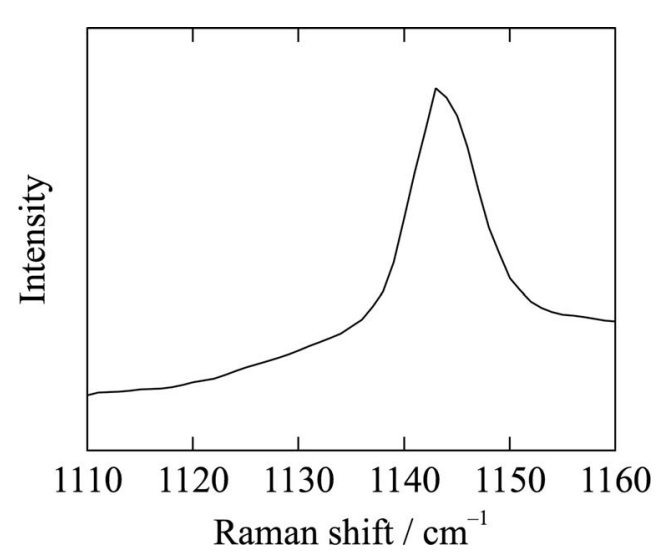

Figure 3. Raman spectrum between $1110-1160 \mathrm{~cm}^{-1}$ of $[18 \mathrm{C} 6 \cdot \mathrm{K}]\left[\mathrm{O}_{2}\right]$ at $50^{\circ} \mathrm{C}$. 

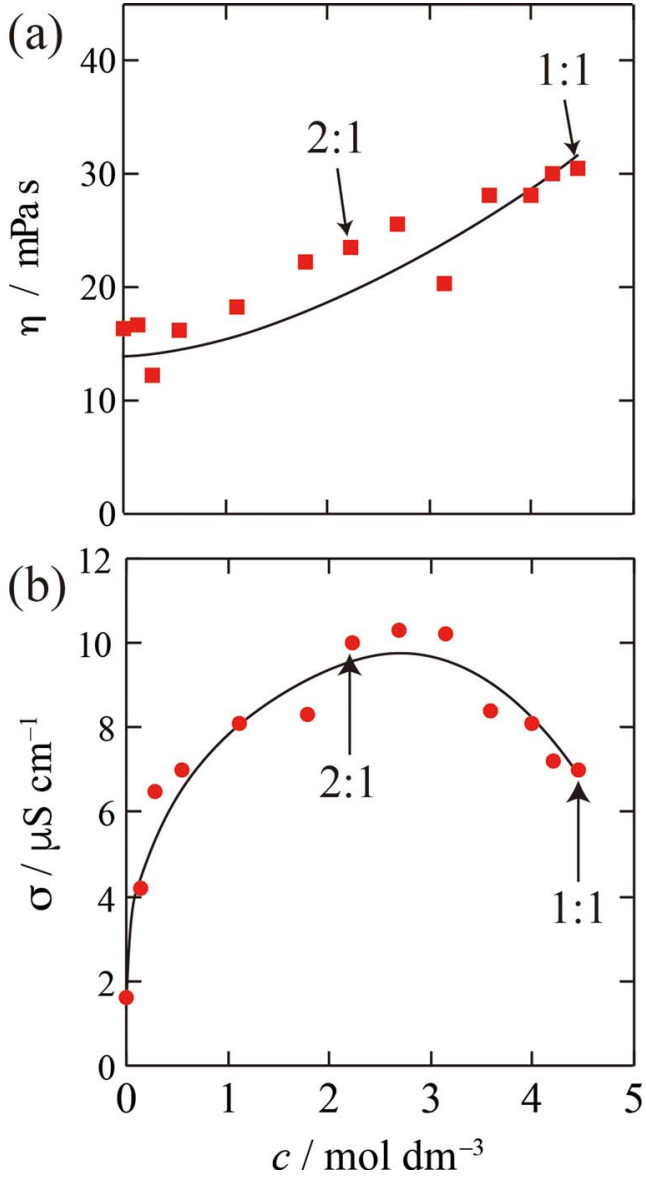

Figure 4. (a) Viscosities and (b) conductivities of $18 \mathrm{C} 6-\mathrm{KO}_{2}$ mixture measured at $50^{\circ} \mathrm{C}$, where solid curves are drawn as a guide to the eye.

similar values in many kinds of ionic liquids. ${ }^{31}$ Therefore, $\Lambda_{\text {ideal }}$ is employed to roughly assess the ionicity of molten $[18 \mathrm{C} 6 \cdot \mathrm{K}]\left[\mathrm{O}_{2}\right]$.

Using a measure of ionicity $\Lambda_{\text {imp }} / \Lambda_{\text {ideal }}$, the ionicity of $[18 \mathrm{C} 6 \cdot \mathrm{K}]\left[\mathrm{O}_{2}\right]$ is estimated to be as low as $5 \times 10^{-4}$. Similarly, low ionicities have been reported in some molten lithium salts with large anion size: ${ }^{32,33}$ the reported lithium salts have low melting points $\left(43^{\circ} \mathrm{C}\right.$ and $120^{\circ} \mathrm{C}$ ) - due to low lattice energy - and low ionic conductivities $\left(0.1-10 \mu \mathrm{S} \mathrm{cm}^{-1}\right)$ even at molten states. Such covalency is contrast to superionic conductors such as AgI-based compounds, ${ }^{34}$ which also have large disparity between cation and anion size; however, the AgIbased superionic conductor cannot melt at ambient temperature (glass transition at as high as $260^{\circ} \mathrm{C}$ ), ${ }^{34}$ indicating less disparity between cation and anion size than those in the lithium salt and $[18 \mathrm{C} 6 \cdot \mathrm{K}]\left[\mathrm{O}_{2}\right]$. In the lithium salt with extremely large disparity of ion size between $\mathrm{Li}^{+}$and anion, it is supposed that $\mathrm{Li}^{+}$ion is trapped in its anionic cage formed by several nucleophilic $\mathrm{O}$ and $\mathrm{F}$ atoms. ${ }^{33}$ We speculate that, in molten $[18 \mathrm{C} 6 \cdot \mathrm{K}]\left[\mathrm{O}_{2}\right]$, cationic cage would form to trap the nucleophilic $\mathrm{O}_{2}{ }^{-}$anions. Consequently, the low melting points and low ionicity in $[18 \mathrm{C} 6 \cdot \mathrm{K}]\left[\mathrm{O}_{2}\right]$-also different from conventional ionic liquids with high ionicity — should be caused by large disparity between cation and anion size.

Although the conductivity of $[18 \mathrm{C} 6 \cdot \mathrm{K}]\left[\mathrm{O}_{2}\right]$ is poor, the reported values of some radical-containing ionic liquids are within one order of magnitude: ${ }^{35,36} 4.4 \times 10^{-5} \mathrm{~S} \mathrm{~cm}^{-1}$ at $70^{\circ} \mathrm{C}$ for a 2,2,6,6tetramethyl-1-piperidinyloxyl (TEMPO) radical-containing IL [1octyl-3-methylimidazolium][TEMPO-OSO ${ }_{3}$ ], $1.0 \times 10^{-6} \mathrm{~S} \mathrm{~cm}^{-1}$ at $27^{\circ} \mathrm{C}$ for a 3,5-di-tert-butyl-1,2-semiquinonate monoanion (DBSQ $\cdot^{-}$) radical-containing ionic liquid $\left[\mathrm{P}_{14,6,6,6}\right]_{2}\left[\mathrm{Co}(\mathrm{DBSQ})_{2}\left(\mathrm{bpy}(\mathrm{COO})_{2}\right)\right]$, where $\mathrm{P}_{14,6,6,6}=$ trihexyl(tetradecyl)phosphonium and bpy $=2,2$ ' bipyridine. It is also notable that $[18 \mathrm{C} 6 \cdot \mathrm{K}]\left[\mathrm{O}_{2}\right]$ has relatively low viscosity among radical-containing ionic liquids. The reported value for [1-alkyl-3-methylimidazolium][TEMPO-OSO ${ }_{3}$ ] is $>400 \mathrm{mPa} \mathrm{s}$ even at $70^{\circ} \mathrm{C}$, and for $\left[\mathrm{P}_{14,6,6,6}\right]_{2}\left[\mathrm{Co}(\mathrm{DBSQ})_{2}\left(\mathrm{bpy}(\mathrm{COO})_{2}\right)\right]$ is $>10^{3}$ $\mathrm{mPa} s$ at $27^{\circ} \mathrm{C}$. The high fluidity could be advantageous as magnetic fluids and radical reactions.

Amount of remaining superoxide anions in $18 \mathrm{C6}-\mathrm{KO}_{2}$ mixture.--It is worth checking the amount of remaining superoxide anions through the reaction of $18 \mathrm{C} 6$ and $\mathrm{KO}_{2}$. A promising method for quantitative analysis is magnetization measurements since a $\mathrm{O}_{2}{ }^{-}$ anion has one unpaired electron which usually shows Curie paramagnetism with the spin quantum number $S=1 / 2$ near RT. ${ }^{1-14,17}$ In Curie paramagnetic state magnetic susceptibility $\chi=M / H$ (where $M$ is magnetization and $H$ is magnetic field) shows temperature dependence as follows:

$$
\chi=C /\left(T-T_{\mathrm{w}}\right)+\chi_{0}
$$

where $C$ is Curie constant, $T_{\mathrm{w}}$ is Weiss temperature, $\chi_{0}$ is temperature independent diamagnetic term due to presence of 18C6. The Curie constants for $18 \mathrm{C} 6-\mathrm{KO}_{2}$ mixture was estimated to be 0.37 , in good agreement with the ideal value of $0.375 \mathrm{emu} \mathrm{K} \mathrm{mol}^{-1}$ for the spin quantum number $S=1 / 2$ assuming the $g$-factor to be 2 . These results indicate that in $18 \mathrm{C} 6-\mathrm{KO}_{2}$ mixture $95 \%$ of $\mathrm{O}_{2}{ }^{-}$remains via preparation process. It may be suggested that $\mathrm{O}_{2}{ }^{-}$reacted with impurities such as $\mathrm{H}_{2} \mathrm{O}$ in starting materials or crownether itself. Suppose the water contained in the $18 \mathrm{C} 6$ reagent i.e. $600 \mathrm{ppm}$ completely reacted, $0.4 \%$ of $\mathrm{O}_{2}{ }^{-}$in the $18 \mathrm{C} 6-\mathrm{KO}_{2}$ would be decomposed. Since crown ethers have large stability constants with alkali cations than glymes (e.g. log $K=6.07$ for $18 \mathrm{C} 6$ in methanol at $\left.25^{\circ} \mathrm{C}\right),{ }^{37}$ the $1: 1$ mixture of ether and $\mathrm{KO}_{2}$ may have less free ether molecules for the case of crown ethers, giving less opportunities for decomposition of the organic ligands and longer term stability of superoxide anions.

Phase separation below melting point.-The magnetic behavior of $1: 118 \mathrm{C} 6-\mathrm{KO}_{2}$ mixture below $300 \mathrm{~K}$ is similar to that of pristine $\mathrm{KO}_{2}$ (see Figure 5), in that both show anomalies i.e. changes in their gradients at ca. $230 \mathrm{~K}$ and $200 \mathrm{~K}$. Note that the $\chi T-T$ plot is taken to emphasize the anomalies. These anomalies are assigned as structural transitions of pure $\mathrm{KO}_{2},{ }^{11-13}$ evidencing that $\mathrm{KO}_{2}$ phase is present in the $18 \mathrm{C} 6-\mathrm{KO}_{2}$ mixture below $300 \mathrm{~K}$. The presence of $\mathrm{KO}_{2}$ phase was also suggested by X-ray diffraction measurements of $18 \mathrm{C} 6-\mathrm{KO}_{2}$ mixture at RT (not shown). These results imply that below melting point 1:1 $18 \mathrm{C} 6-\mathrm{KO}_{2}$ mixture undergoes phase separation from $[18 \mathrm{C} 6 \cdot \mathrm{K}]\left[\mathrm{O}_{2}\right]$ liquid phase to solid $18 \mathrm{C} 6$ and solid $\mathrm{KO}_{2}$ phases. Since pure 18C6 has a closed shell configuration, its magnetism is so-called Larmor diamagnetism i.e. magnetic susceptibility $\chi_{18 \mathrm{C} 6}$ is

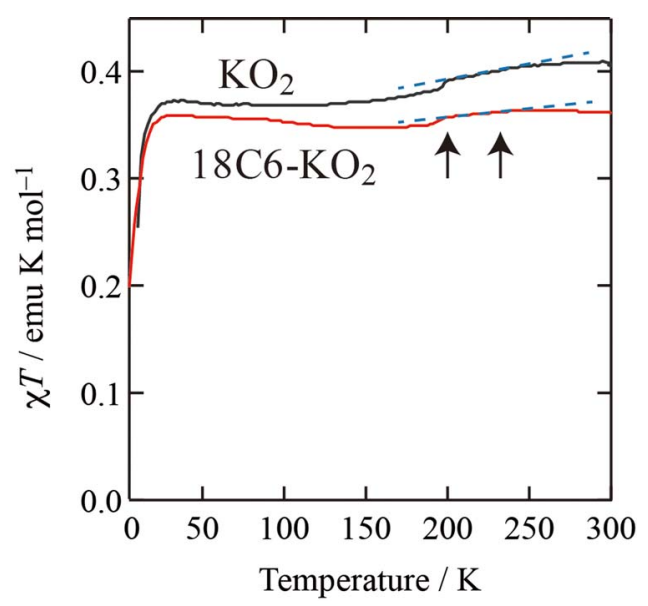

Figure 5. $\chi T-T$ plot (product of magnetic susceptibility and temperature vs. temperature) of pristine $\mathrm{KO}_{2}$ and $18 \mathrm{C} 6-\mathrm{KO}_{2}$ mixture, where dashed lines and arrows indicate structural phase transitions. 


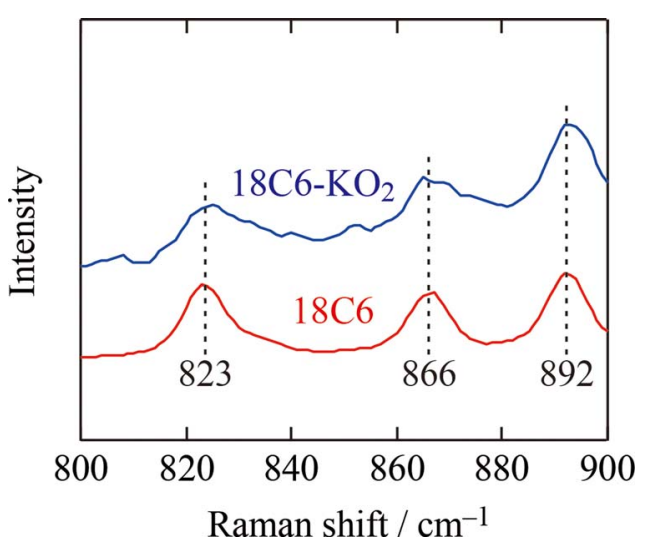

Figure 6. Raman spectra between $800-900 \mathrm{~cm}^{-1}$ of pure $18 \mathrm{C} 6$ and $18 \mathrm{C} 6-\mathrm{KO}_{2}$ mixture at RT, where dashed lines are a guide to the eye.

negative and temperature independent. The difference in $\chi T$ between 18C6- $\mathrm{KO}_{2}$ and pure $\mathrm{KO}_{2}$ seems proportional to $T$, which should be partially caused by $\chi_{18 \mathrm{C} 6} T$, where temperature independent $\chi_{18 \mathrm{C} 6}$ was measured to be ca. $-2 \times 10^{-5} \mathrm{emu} \mathrm{mol}^{-1}$.

The presence of pure 18C6 at solid state is evidenced from Raman measurements below the melting point of $18 \mathrm{C} 6-\mathrm{KO}_{2}$ mixture. Figure 6 shows Raman spectra at RT for pristine $18 \mathrm{C} 6$ and the $18 \mathrm{C} 6-\mathrm{KO}_{2}$ mixture -once heated at $50^{\circ} \mathrm{C}$ for $30 \mathrm{~min}$ then cooled to RT- are quite similar: both spectra show bands at $823 \mathrm{~cm}^{-1}, 866 \mathrm{~cm}^{-1}, 892$ $\mathrm{cm}^{-1}$, proving that pure $18 \mathrm{C} 6$ reappears when $18 \mathrm{C} 6-\mathrm{KO}_{2}$ mixture is cooled to RT. Consequently, below melting point of $1: 118 \mathrm{C} 6-\mathrm{KO}_{2}$ mixture pure $\mathrm{KO}_{2}$ and pure $18 \mathrm{C} 6$ phases coexist i.e. phase separation occurs while above melting point a liquid complex $\left[18 \mathrm{C} 6 \cdot \mathrm{K}^{2}\left[\mathrm{O}_{2}\right]\right.$ forms.

DSC measurements.-DSC curves (heating process) show that the melting points for pure $18 \mathrm{C} 6$ and $18 \mathrm{C} 6-\mathrm{KO}_{2}$ mixture are $37^{\circ} \mathrm{C}$ and $38^{\circ} \mathrm{C}$, respectively (see Fig. 7). The values are very close, supporting the abovementioned phase separation. A tiny exothermic peak in addition to a large exothermic one was observed for each DSC curve (cooling process). For $18 \mathrm{C} 6-\mathrm{KO}_{2}$ the tiny peak appeared at ca. $38^{\circ} \mathrm{C}$, just below the melting point, while the large peak was seen at ca. $32^{\circ} \mathrm{C}$. For pure $18 \mathrm{C} 6$, instead, supercooling was observed: the tiny peak was seen far below the melting point $\left(\mathrm{ca} .16^{\circ} \mathrm{C}\right)$, followed by the large peak at ca. $7^{\circ} \mathrm{C}$. We suggest that in both cases the large peak is caused by freezing and the tiny peak is possibly by conformational change of $18 \mathrm{C} 6 .^{38}$ Although the position of these exothermic peaks should depend on cooling rate, the higher temperatures of phase transitions for $18 \mathrm{C} 6-\mathrm{KO}_{2}$ than for pure $18 \mathrm{C} 6$ may be due to the presence of $\mathrm{KO}_{2}$ particles, which could help phase transition or nucleation of the coexisting $18 \mathrm{C} 6$ matrix.

General discussion.-Above the "melting point" of the 1:1 mixture of $18 \mathrm{C} 6$ and $\mathrm{KO}_{2}$, the solvation of $18 \mathrm{C} 6$ to $\mathrm{K}^{+}$occurs, giving $[18 \mathrm{C} 6 \cdot \mathrm{K}]\left[\mathrm{O}_{2}\right]$ at liquid state. This conclusion is supported by three points: (I) The photograph of the mixture strongly indicates total dissolution of $\mathrm{KO}_{2}$, in that the mixture became transparent at elevated temperature. (II) The Raman spectra clearly showed characteristic bands at ca. $870 \mathrm{~cm}^{-1}$ due to the coordination of $18 \mathrm{C} 6$ to $\mathrm{K}^{+}$. (III) If a $\mathrm{KO}_{2}-18 \mathrm{C} 6$ solution were saturated at lower molar ratio than $1: 1$, the bath properties would be independent at high concentrations; the obtained properties, however, show a concave-down dependence as seen in Fig. 4b. Below the "melting point", on the other hand, the mixture undergoes phase separation into pure $18 \mathrm{C} 6$ and pure $\mathrm{KO}_{2}$. This is evidenced by magnetization and the RT Raman spectra.

Such behavior - high temperature compatibility and low temperature phase separation - is also seen in eutectic haloaluminate ionic liquids: for example, 2:1 mixture of ethylpyridinium bromide (Et$\mathrm{PyrBr})$ and aluminum chloride $\left(\mathrm{AlCl}_{3}\right)$ undergoes phase separation
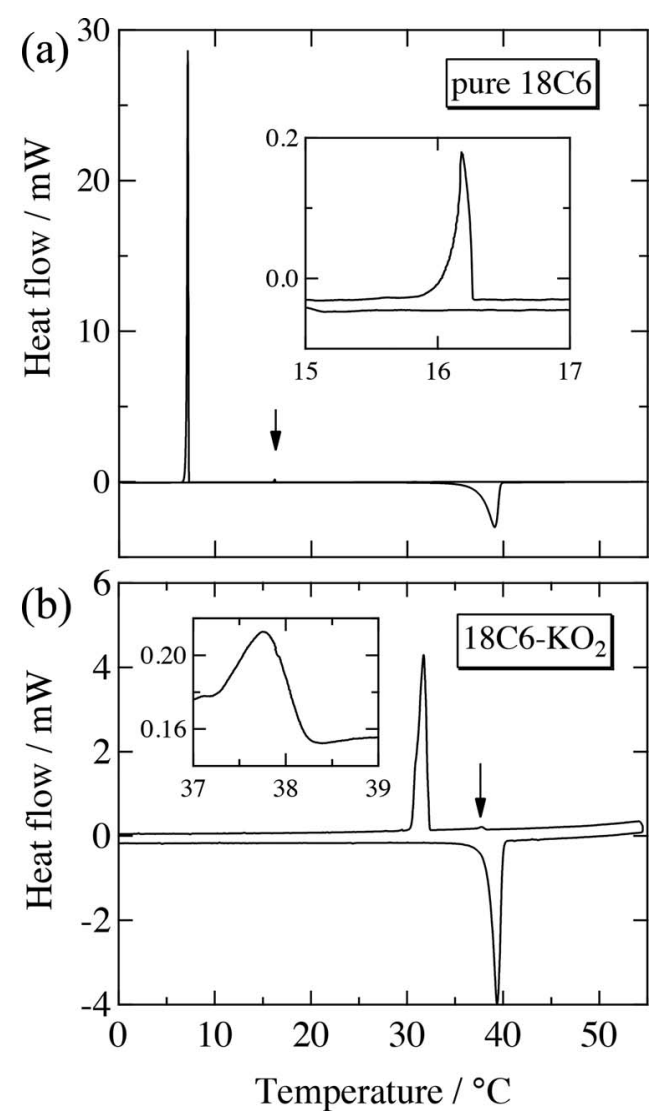

Figure 7. DSC curves for (a) pure $18 \mathrm{C} 6$ and (b) $18 \mathrm{C} 6-\mathrm{KO}_{2}$ mixture, where arrows indicate "tiny" peaks and insets show enlarged plots of "tiny" peaks due to conformational changes in $18 \mathrm{C} 6$ (see text for details).

from a liquid phase to EtPyrBr and the $1: 1$ phase, [EtPyr] $\left[\mathrm{AlCl}_{3} \mathrm{Br}\right] .{ }^{39}$ It should be stressed that state below melting points does not matter for determination as ionic liquids. In this respect, the $1: 118 \mathrm{C} 6-\mathrm{KO}_{2}$ mixture becomes an "ionic liquid" above the melting point of pure 18 C6.

Apparently, the stabilization of $[18 \mathrm{C} 6 \cdot \mathrm{K}]$ complex is contributed not only by the electrostatic interaction but also by the induction interaction between metal cation and ligand. Mandai et al. reported that using pentaglyme (G5), in which six oxygen atoms are involved within a single molecule as well as $18 \mathrm{C} 6$, a stable solvate forms when the ion-dipole interaction between $\mathrm{K}^{+}$and G5 overwhelms the ion-ion interaction between $\mathrm{K}^{+}$and anion. ${ }^{25}$ It is interesting that the melting point for the $[18 \mathrm{C} 6 \cdot \mathrm{K}]\left[\mathrm{O}_{2}\right]$ is near that of pure $18 \mathrm{C} 6$. In pure $18 \mathrm{C} 6$, its conformation changes at its melting point: below melting point, Raman bands characteristic to $C_{i}$ conformation appear at $416 \mathrm{~cm}^{-1}$ and $582 \mathrm{~cm}^{-1},{ }^{40}$ which disappear above melting point (not shown). Therefore, it seems that the conformational change of pure 18C6, which increases $\mathrm{K}^{+}-18 \mathrm{C} 6$ interaction, is a key to form the stable solvate $[18 \mathrm{C} 6 \cdot \mathrm{K}]\left[\mathrm{O}_{2}\right]$ at high temperature. Since $\mathrm{O}_{2}{ }^{-}$is a strong Lewis base, the ion-ion interaction must be strong, giving the phase separation. Such phase separation has not been reported in other crownether$\mathrm{K}^{+}$salt mixtures when larger anions or weaker Lewis bases are used, ${ }^{25-28}$ indicating that the $\mathrm{K}^{+}-\mathrm{O}_{2}^{-}$and the $\mathrm{K}^{+}-18 \mathrm{C} 6$ interaction is comparable.

\section{Conclusions}

We prepared the first "ionic liquid" containing superoxide anion radical moiety. An "ionic liquid state" consisting of superoxide radical anions and potassium 18-crown-6-ether (18C6) complex cations emerges only above $38^{\circ} \mathrm{C}$, while below $38^{\circ} \mathrm{C}$ a phase separation occurs 
to form the parent phases: solid $18 \mathrm{C} 6$ and $\mathrm{KO}_{2}$. The ion-dipole interaction between $\mathrm{K}^{+}$and $18 \mathrm{C} 6$ competes with the ion-ion interaction between $\mathrm{K}^{+}$and $\mathrm{O}_{2}{ }^{-}$, resulting in low-temperature phase separation and high-temperature solvation. The high temperature solvation of $18 \mathrm{C} 6$ to $\mathrm{K}^{+}$may be assisted by melting and/or conformational change of pure 18C6. Among radical-containing ionic liquids, the liquid 18C6$\mathrm{KO}_{2}$ mixture has high fluidity and comparable conductivity. The high fluidity of $[18 \mathrm{C} 6 \cdot \mathrm{K}]\left[\mathrm{O}_{2}\right]$ could be advantageous in the viewpoint of magnetic fluid. The findings show stabilization of superoxide radical anions at liquid state with high concentration; since superoxide radical has close relationships with reactions in air batteries, organic synthesis, and enzyme catalysis, the findings could deepen understanding of many radical reactions in bioscience and basic chemistry.

\section{Acknowledgments}

We thank Prof. H. Kageyama for assistance with magnetization measurements. This work was supported by Grants-in-Aid for challenging Exploratory Research (No. 25630337), by Grant-in-Aid for Scientific Research (A) (No. 16H02411), and by Grant-in-Aid for Young Scientists (B) (No. 15K18253) from the Japan Society for the Promotion of Science (JSPS).

\section{References}

1. O. Milstein, A. Hüttermann, R. Fründ, and H.-D. Lüdemann, Appl. Microbiol. Biotechnol., 40, 760 (1994).

2. E. P. Krinichnaya, A. P. Moravsky, O. Efimov, J. W. Sobczak, K. Winkler, W. Kutner, and A. L. Balch, J. Mater. Chem., 15, 1468 (2005).

3. M. Hayyan, F. S. Mjalli, M. A. Hashim, and I. M. AlNashef, Ind. Eng. Chem. Res., 51, $10546(2012)$

4. D. T. Sawyer and J. S. Valentine, Acc. Chem. Res., 14, 393 (1981).

5. J. S. Valentine and A. B. Curtis, J. Am. Chem. Soc., 97, 224 (1975).

6. D. Ishikawa, A. Hashimoto, A. Kitada, and K. Murase, ECS Trans., 58(25), 33 (2014).

7. Y. Katayama, H. Onodera, M. Yamagata, and T. Miura, J. Electrochem. Soc., 151(1), A59 (2004).

8. D. Zhang, T. Okajima, F. Matsumoto, and T. Ohsaka, J. Electrochem. Soc., 151(4), D31 (2004).

9. Y. Yan, T. Khoo, C. Pozo-Gonzalo, A. F. Hollenkamp, P. C. Howlett D. R. MacFarlane, and M. Forsyth, J. Electrochem. Soc., 161(6), A974 (2014).

10. M. M. Islam and T. Ohsaka, J. Phys. Chem. C, 112(4), 1269 (2008).
11. A. Zumsteg, M. Ziegler, W. Känzig, and M. Bösch, Phys. Cond Matter, 17, 267 (1974).

12. W. Känzig and M. Labhart, J. Phys. Colloques, 37, C7-39 (1976).

13. M. Labhart, D. Raoux, W. Känzig, and M. A. Bösch, Phys. Rev. B, 20, 53 (1979).

14. S. Riyadi, S. Giriyapura, R. A. de Groot, A. Caretta, P. H. M. van Loosdrecht, T. T. M. Palstra, and G. R. Blake, Chem. Mater, 23, 1578 (2011).

15. S. Giriyapura, B. Zhang, R. A. de Groot, G. A. de Wijs, A. Caretta, P. H. M. van Loosdrecht, W. Kockelmann, T. T. M. Palstra, and G. R. Blake, Inorg. Chem., 53, 496 (2014)

16. K. Yamaguchi, T. S. Calderwood, and D. T. Sawyer, Inorg. Chem., 25, 1289 (1986).

17. P. D. C. Dietzel, R. K. Kremer, and M. Jansen, J. Am. Chem. Soc., 126, 4689 (2004).

18. K. U. Schwenke, S. Meini, X. Wu, H. A. Gasteiger, and M. Piana, Phys. Chem. Chem Phys., 15, 11830 (2013).

19. P. Hartmann, C. L. Bender, M. Vračar, A. K. Dürr, A. Garsuch, J. Janek, and P. Adelhelm, Nat. Mater, 12, 228 (2013).

20. H. Jung, J. Hassoun, J. Park, Y. Sun, and B. Scrosati, Nat. Chem., 4, 579 (2012).

21. R. Black, S. Oh, J. Lee, T. Yim, B. Adams, and L. F. Nazar, J. Am. Chem. Soc., 134, 2902 (2012).

22. X. Ren and Y. Wu, J. Am. Chem. Soc., 135, 2923 (2013).

23. X. Ren, K. Lau, M. Yu, X. Bi, E. Kreidler, L. A. Curtiss, and Y. Wu, ACS Appl. Mater Interfaces, 6, 19299 (2014)

24. T. Mandai, K. Yoshida, K. Ueno, K. Dokko, and M. Watanabe, Phys. Chem. Chem Phys., 16, 8761 (2014).

25. T. Mandai, S. Tsuzuki, K. Ueno, K. Dokko, and M. Watanabe, Phys. Chem. Chem Phys., 17, 2838 (2015)

26. Y. Song, H. Jing, B. Li, and D. Bai, Chem. Eur. J., 17, 8731 (2011).

27. A. J. Pawlak and M. L. Dietz, Sep. Sci. Technol., 49(18), 2847 (2014).

28. Y. Song, C. Cheng, and H. Jing, Chem. Eur. J., 20, 12894 (2014).

29. D. Ishikawa, A. Kitada, K. Fukami, and K. Murase, ECS Trans., 64(4), 21 (2014).

30. J. Sangster, J. Phase Equilib. Diffus., 34, 43 (2013).

31. K. Ueno, K. Yoshida, M. Tsuchiya, N. Tachikawa, K. Dokko, and M. Watanabe, J. Phys. Chem. B, 116, 11323 (2012).

32. W. Xu and C. A. Angell, Electrochem. Solid-State Lett., 3, 366 (2000).

33. H. Tokuda, S. Tabata, Md. A. B. H. Susan, K. Hayamizu, and M. Watanabe, J. Phys Chem. B, 108, 11995 (2004).

34. W. Xu, E. I. Cooper, and C. A. Angell, J. Phys. Chem. B, 107, 6170 (2003)

35. Y. Yoshida, H. Tanaka, and G. Saito, Chem. Lett., 36(9), 1096 (2007)

36. Y. Yoshida, H. Tanaka, G. Saito, L. Ouahab, H. Yoshida, and N. Sato, Inorg. Chem., 48, 9989 (2009)

37. A. Varnek, G. Wipff, V. P. Solov'ev, and A. F. Solotnov, J. Chem. Inf. Comput. Sci., 42(4), 812 (2002)

38. N. A. Al-Jallal, A. A. Al-Kahtani, and A. A. El-Azhary, J. Phys. Chem. A, 109, 3694 (2005).

39. F. H. Hurley and T. P. Wier Jr,, J. Electrochem. Soc., 98, 203 (1951).

40. H. Matsuura, K. Fukuhara, K. Ikeda, and M. Tachikake, J. Chem. Soc., Chem. Commun., 1989, 1814 (1989). 